\title{
An Inquiry into the Urban Landscape of Multicultural Cities
}

\author{
Mohsen Aboutorabi \\ SCHOOL OF ARCHITECTURE, BIRMINGHAM CITY UNIVERSITY, \\ UK
}

\begin{abstract}
The social landscape of most of the European cities is rapidly changing from a single to the multiple cultural communities under the influence of globalisation and human movement. Such a rapid change has moved the concept of singularity from the many discourses on the socio-cultural, economic and physical aspect of the city to a more complex cross-cultural dialogue.

On the socio-cultural dimension, the subject of social cohesion and social inclusion where different social and ethnic groups can live together to form a larger urban community yet retain their cultural identity has become an important issue that concerns many cities. In the main, these issues have been analysed using social, economic and political science perspectives. The influence of the built environment as an important factor in determining cultural and ethical identity has been inadequately addressed

The paper reviews selected theoretical concepts to verify the exact meaning of culture, cultural identity, social space and social spatiality in the context of ethnic societies. These issues are then examined in the Muslim ethnic neighbourhoods in Birmingham to find out to what extent the urban character of their neighbourhoods represents their cultural identity. The paper concludes how the understanding of cultural norms can contribute to the development of an alternative approach for planning and regeneration practice.
\end{abstract}

Keywords: Culture, Identity, cultural landscape, social cohesion.

\section{Introduction:}

Urban population of most of the multicultural cities in Europe includes three distinguished communities. The first one is the original community, second are the migrants from developing countries and third are migrants from European countries. Social transformation of these cities from a single to a multiple culture has had an impact on the urban landscape and social cohesion of the city.

There is a general view that cultural background, ethnicity and income foster both integration and separation of social groups. These factors on one hand foster formation of cultural/ethnic clusters maximising group social interaction, on the other hand, they separate and distinguish groups from each other (Duncan \& Ley, 1993; 
$5^{\text {th }}$ International Conference on Civil Engineering, Architecture and Urban Planning Elites

Gilbert \& Gugler, 1992; Rapoport, 1997). Grouping and locations of ethnic groups in the city, therefore, reflects not only income but cultural values and preference (Newman 1972; Agnew, 1984). In some cases, grouping allows the resetting of public spaces to further increase the possibility of performing their cultural behaviour.

Approaches to address social problems in the multicultural cities have mostly been taken in the context of political discourses uttering the idea of integration and, in some countries prohibiting the practice of the ethnic cultural norms. The influence of the built environment as an important factor contributing to the formation of a harmonious urban society through the representation of cultural and ethical identities of various societies has not been paid attention. This has changed the social landscape of most of the multicultural cities to include a variety of segregated ethnic communities. One consequence of this is that many communities especially the youth, feel invisible, ignored and detached from both their ethnic identity and the urban community they live in. The paper aims to highlight how to address this problem through developing a shared urban identity for increasing the sense of belonging for all cultural groups.

The paper starts with presenting short reviews of the definition of three phenomena of culture, identity, and place. It explores the complex concept of culture, identifying its structural principles, their rules and values and their dominant forces regulating the social behaviour and forming the cultural identity. It demonstrates how religion principle, for certain cultural groups act as a dominating force regulating their social behaviour and representing their identity. This followed by discussion on space and place in relation to culture, time, space and the notion of spatiality to demonstrate the cultural dimension of space. The case study focuses on analysing the transformation of the urban landscape of public places within the Muslim ethnic neighbourhoods in response to their socio-cultural norms. And finally, the paper recommends for an alternative approach to urban planning and regeneration in response to cultural requirements.

\section{2- Culture, Identity and Place}

\section{$\underline{2.1 \text { Culture }}$}

The complex concept of culture has been defined by varying points of view in many disciplines. And since all these definitions expressing the social character of people, one could find a common ground shared by all. I will start to review some of these definitions briefly to define a cultural concept in relation to the subject of this paper.

In psychology, culture signifies a set of shared values placed within the psychological structure of a person providing a mental framework through which people observe the world and others. These shared values act as a medium relating a person to the cultural group allowing interaction and sharing common meanings and behaviour (Valsiner 2007; Kidd, 2002). Freud (1923) presents the same view, arguing that the superego of our mind guides us to follow the cultural rules of the society we 
$5^{\text {th }}$ International Conference on Civil Engineering, Architecture and Urban Planning Elites

have been brought up. In this view, culture becomes 'an inherent, systemic organizer of the psychological systems of individual persons', that the change of environment will not stop its functioning (Boesch, 1991-inValsiner, 2007:21). This means if a person or a group migrate from their home country to another country, their cultural norms and behaviour will not change.

In Geography, culture is defined in terms of 'meaning-making and human imagining' (Mitchell, 2000: 13). These imagining, and meanings are 'formed in discourse, language, symbols, signs and texts' (Lewis, 2002: 13). Culture then in its broadest sense refers to a set of qualities/order defining the social and productive aspect of the society. On the social aspect, culture refers to the shared values, belief, habits and behaviour characterizing the life of people (Mitchell, 2000). This represents culture as the 'whole way of life' of a group of people, 'encompassing language, dress, food, habits, music, housing styles, religion, family structures and most importantly, values' (Mitchell, 2000: 13). In this 'whole way of life' definition, some cultural resources such as religion and its characteristic activities become the 'whole way of life' that makes life worth living (Elliot, T. S. 1962). System of belief and social norms has been considered as the most important contributing factors in shaping the culture. Seufert (1997) demonstrates how religious criteria define social boundaries among the Muslim Kurdish migrants living in Istanbul and how overlooking these boundaries by members of the tribe isolate them from their closest relatives.

On the productive aspect, culture refers to the cultural practices representing the intellectual, literary, artistic and creative production of a society in a historical period (Jenks,1993; Mitchell, 2000).

The productive aspects of each culture are based on the individual sense of creativity stimulated by the cultural values (Runco,2014). In this view, the two social and productive aspects of the culture are interconnected in the way that social aspect as the process sets images and meaning for the products.

Regarding the fixed and transient nature of culture, Valsiner (2007) emphasises on the stable nature of culture and writes 'Even if historical changes take place in a given society, culture is expected to be characterized by its stability' (P:22). Lewis (2002) presents an opposite view, arguing that the imagining and meanings that construct culture are not fixed and are subject to change through the time, place and human action since the assemblage of meaning was 'for a purpose within a particular historical and spatial context' (P:13).

Whether the process of globalization would finally lead to cultural homogenization or not is a complex debate that requires assessing the stability and strength of the local culture. However, in the interaction between cultures in the global world, some cultural principles i.e. religion and its norms, for some society, stays the same with no change since, as was mentioned above, religion for some cultural groups is the way of life or makes life worthy of living. For these societies perception of life, 'imagining and meaning', are constructed according to the exclusive nature of their belief which would not be influenced by global flows. 
$5^{\text {th }}$ International Conference on Civil Engineering, Architecture and Urban Planning Elites

The above review generally portrayed culture as the society's shared social construction, including the system of belief, social order, and social relation, to formulate common values. And this social construction as a process fuels ideas and imagination for social production representing the culture.

\subsection{Sociocultural Identity:}

Cultural identity is interpreted in two different ways; one is that it is formed by shared historical and cultural codes representing a group of people. These shared cultural features remain 'the same over time, even as the membership of persons in a culture change from generation to generation' (Valsiner 2007:22). Knox (2010) argues that some social groups oppose integration with other social groups with different religious and ethnicity to preserve their group identity. In this way past plays a dominant role in the formation of identity as a fixed essence.

Social identity is formed by the association of individuals to a group defining the group identity which individual feels belongs to (Benwell and Stokoe, 2007, PP 18 \&25). Identity for an ethnic group at the local level is what individuals relate themselves to a social group with similar cultural background and at international level, means individuals links to the country of origin-homeland (Honeyford, 1988).

Identity, therefore, refers to our representation at the time in relation to cultural resources. Such a representation embraces all shared characteristics or particularity of objective, 'production', and subjective 'social practices' of a cultural group. The objective or visible factors include place, physical appearance, and artistic production which are fixed located at the forefront of representing both individual and group identity, whereas, the practice of subjective factors such as social behaviour, belief, and the worldview may vary among the individual within a cultural group.

The subjective factors for the ethnic migrant groups, especially the older generation, whose historical background has been away from the land they live in stays always alive in their memory. The past is not a frozen picture, but a living memory which only shared and understood by the members of the community. The constant practices of cultural assets such as language, religion and tradition among the ethnic groups continuously reconstruct the livelihood of the past (Moghaddam, 2002). While the older generation of ethnic groups within their exclusive society reconstruct the cultural behaviour of their country of origin, to demonstrate their identity - who they are - the younger generation who are born abroad are exposed to two cultural contexts of the exclusive ethnic background and an inclusive cultural environment they have been brought up and educated. This exposure to the two exclusive and inclusive cultural contexts creates a potential for individuals to develop an identity to include both. Bhabha (1996) argues that exposure to two culture develops 'in-between' culture "baffling alike and different the parent culture." (In Hall \& Du Gay, 1996, pp.5460)

Over the past two decades, Religion has become the priority identity among the Muslims living in Europe. Whereas in most of the Muslim countries, religion is 
$5^{\text {th }}$ International Conference on Civil Engineering, Architecture and Urban Planning Elites

considered as national identity, for most of Muslim living abroad, it is a personal identity which distinguishes them from others (Poole-in Alcoff \& Mendieta, 2003: 27).

\subsection{Place and space:}

Having established definitions for culture and cultural identity, this section further proceeds with discussion on space and place in relation to culture.

Michel Foucault provides a broad definition of space; 'The space in which we live, which draws us out of ourselves, in which the erosion of our lives, our time and our history occurs, the space that claws and gnaws at us, is also, in itself, a heterogeneous space [.....] we live inside a set of relations' (Kham, 2000).Tuna views space more in relation to human being and define it 'as the embodiment of feelings, images and thoughts of those who live, work or otherwise deal with that space' (Tuan-in Jiven \& Larkham, 2003:p10). I further define the above definition of 'space' in the context of this paper as the three-dimensional setting within or between places for social behaviour of people. In short, I am referring to the social space in which we live and create relationship with other people, societies, and surroundings.

While in most of the literature space has an abstract and subjective definition, the place has been interpreted in a more comprehensible and objective way. Castello refers to the place as a 'qualified space' and that changes the subjective or abstract notion of space to a more objective notion of place that could be experienced (Castello, 2010-in Wesener, 2013 P. 80). Places are parts of 'human environments where meanings, activities and a specific landscape are all implicated and enfolded by each other' (Relph, 1992-in Hague \& Jenkins:4).

In theoretical discussions three types of place have been identified: the first one is the material or physical dimension of place what Castello refers to as 'place of aura', including the physical characteristic of the place, its landscape, public spaces, and materials. The second type is 'place of memory' referring to time and space. And the third type is 'place of polarity' referring to the social dimension of the place including social interaction and cultural social structure (Castello 2010-in Wesener, 2013:79).

Place, therefore, has some association with our life either as a memory of our direct experience of being there, or indirect experience developed through words, stories, and images. I know the place that I was brought up, I have heard about the central park in New York, I have seen images of that place on TV. Proshansky et al., (1983) argues that even our ongoing experience of a physical setting move to the stage of being remembered'(P77). Our memory of the place is therefore constructed through both our direct experience of the place being there and seeing its physical appearance and indirect experience through narratives and images of the place. The memories of direct experience generally give meaning to a place since they refer to our social life that has been taking place there. In this sense, space and place become the integrated part of each other as body and soul, where the body represents the physical appearance and the soul its social space.

Proshansky et al. (1983) further elucidate that the relationship of people to place involves both its physical and 'social meanings and belief attached to it' by its residents 
$5^{\text {th }}$ International Conference on Civil Engineering, Architecture and Urban Planning Elites

(P177). This relationship sets out a foundation for place-identity which in the context of culture relates to self-identity and includes a variety of images and memories of the past and present (Watson 2007).

Setha Low 2014- in Gieseking, \& Mangold (2014): 34) proposes the concept of 'spatializing culture' to discuss the relationship between culture, space, and place. She demonstrates the multifaceted relationship between people and place including aspects of social and historical dimension which might have originated in other places. I take the term 'spatializing culture' used by Setha Low especially the reference to its historical origin to demonstrate how different cultural groups organise their urban spaces to suit their cultural performances and these spaces become places representing their cultural identity.

The place-identity of an ethnic group in a multicultural society, therefore, represents 'not only, different uses and experiences with space and place, but corresponding variations in the social values, meanings, and ideas which underlie the use of those spaces.' (Proshansky et al. 1983: P78). Each place, therefore, embodies a set of meanings expressing its particularity in relation to practice of socio-cultural norms and behaviour of each group defining its identity.

\section{The Case Study}

\subsection{Context and Method:}

The four subjects of culture, identity, space and place discussed in this paper will be examined broadly in the context of cultural minority neighbourhoods in Birmingham with more attention to the Muslim areas since they are the largest ethnic groups with rich cultural and religious background.

Birmingham is a culturally diverse City. According to the 2011 Population Census, $53.1 \%$ of residents were white British and $46.9 \%$ described themselves from other ethnic groups including 26.62\% Asian British, 8.98\% black British, $4.44 \%$ mixed and $2.03 \%$ other ethnic groups. The term 'ethnic' in social science refers to 'a group sharing a common culture and defined largely by descent and perhaps physical similarity' having similar language, religion, social customs, cultural artefacts and characteristic ways of doing things (Honeyford, 1988: 5).

The largest ethnic groups in Birmingham are Pakistani 13.5\%, Indian 6\%, Caribbean 4.44\% and Bangladeshi 3.03\%. The major religions were $46.1 \%$ Christian, $21.8 \%$ Muslim, 3.02 Sikh, 2.08 Hindu and $19.3 \%$ of residents declared no religion (www.birmingham.gov.uk). These varieties of cultural groups have transformed the urban landscape of the city to multiple neighbourhoods each representing different cultural practices The Birmingham cultural map is an example of Tonkiss statement that 'Culture leaves a kind of 'stain' on the urban landscape, marking out different neighbourhoods in ways which go beyond their economic functions or physical conditions.' (Tonkiss, 2005:40) 
Such a map shows that almost $70 \%$ of these minority ethnic groups are living in neighbourhoods within 12 districts close to the city centre. The location of these ethnic clusters close to the city centre has historically been due to the availability of job around the city centre for early migrants with no skills and educational qualifications (Knox \& Pinch 2010). Cultural background together with low-income level has been continuous forces fostering the formation of cultural/ethnic clusters maximising group social interaction.

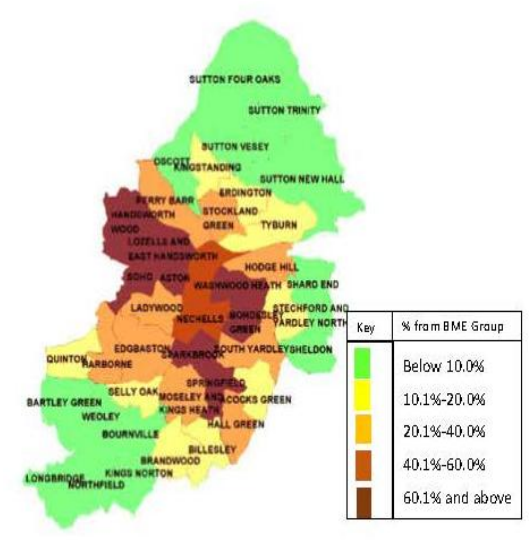

Fig. 1: Black and minority ethnic groups by ward in Birmingham in May 2010. Source: Birmingham City Council

One condition that supports and strengthens the formation of an ethnic community is the feeling of not belonging to the environment they live in. All the story of their life is constructed due to belonging to somewhere else. Ethnic group's attachment to their place, as was discussed above, depends on their memory of the place, and how it represents their cultural identity. These factors strengthen social ties among the ethnic community, facilitate their social behaviour and contribute to shaping their place. What identifies ethnic neighbourhoods are not physical boundaries but spatial boundaries formed by socio-cultural practices that according to Tonkiss (2005) 'gives objective form to a subjective understanding of space..' (p.32). Boundaries of ethnic neighbourhoods are, therefore, defined by the socio- spatial quality of these places including social behaviour, interaction, and use of spaces creating soft barrier defining ethnic identity.

The case study aimed to collect data on the socio-spatial character of the place in relation to the topics discussed in the paper. Its focus was on Muslim neighbourhoods because a: as was discussed in the cultural section they have a stronger cultural community, and b: they have less historical and religious relationship with the British culture than the other two Indian and Caribbean major ethnic groups.

Although the first stage of the case study included interviews, however, the results showed that interviewees' responses were affected by the current socio-political environment concerning the Muslim community. The case study, therefore, concentrated on observing people's behaviour, listening to their conversation, taking notes and pictorial record. I also managed to have few casual conversations with the shop staff especially in the food shops regarding some of the social behaviours that were not clear to me. ${ }^{1}$

\footnotetext{
${ }^{1}$ One interesting casual discussion was about an elderly lady followed by five beautifully dressed young girls going up and down the high street of one of the mixed ethnic neighbourhood. I was told that the lady is marriage agent who is trying to find husband for girls.
} 
$5^{\text {th }}$ International Conference on Civil Engineering, Architecture and Urban Planning Elites

\subsection{Analysis of the outcomes:}

Looking at the social interaction of ethnic groups in the public places reveals the specific characteristic of the cultural behaviour of each group with reference to their traditional/historical background. For example, the cultural behaviour within the neighbourhood of Muslim ethnic groups in Birmingham is similar to what Kazemi and Rahmani discuss regarding the social principles and behaviour of the Muslim society. They write that street in the traditional Muslim cities is a 'space of wandering and happenstance, it is a space to engage with the member of communities without prior arrangement' (Kazimee \& Rahmani, 2003:106). Lapidus (1973) raises the same point by referring to the socio-spatial character of the market in traditional Islamic towns, as the place of mixed urban activities bringing people together and allowing easy movement from one activity to other.

The main street within the Muslim neighbourhoods represents the same character. The multifunctional environment of pedestrian rout- walking, shopping, display of goods and clothes- fosters the social interaction of the group contributing to the livelihood of the place.

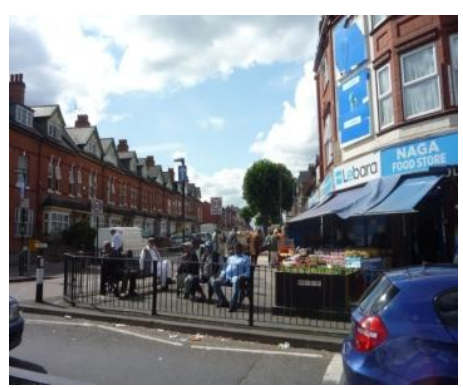

Stratford Road, Spark hill

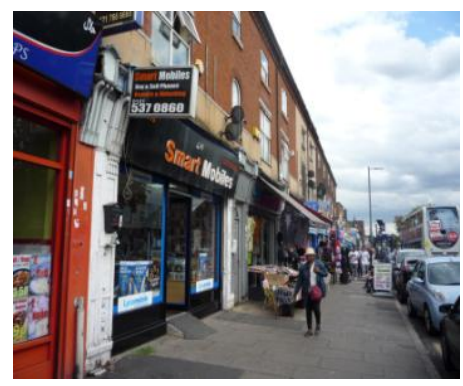

Small Heath

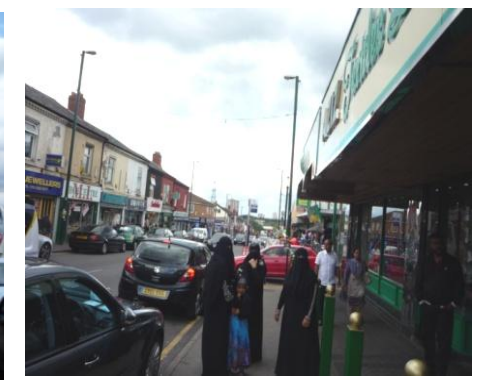

Alum Rock Road

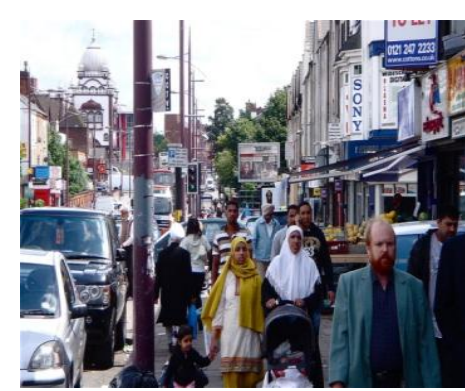

Handsworth

What one generally observes in the minority neighbourhoods is the cultural transformation of the place to form a suitable space for their cultural behaviour. I use the term cultural transformation because these places were not originally produced by their current users but have been altered to suit their cultural behaviour. The process 
$5^{\text {th }}$ International Conference on Civil Engineering, Architecture and Urban Planning Elites

Paris, France

November 2-4, 2018

of transformation of an existing physical place by an ethnic community into a social space suitable for their social practices includes signs and symbols referring to the groups' culture and religion, as well as the way that space is utilised. Here one observes the cultural language and text in shaping the spatial character of the street (Barthes 1977, in: Tonkiss 2005).

The utilization of space is the most noticeable factor since Pedestrian spaces are used for multiple activities in addition to walking.

Here the expansion of shops businesses into the sidewalks has contributed to the livelihood of the street. This very open and spread/disordered functional organisation of space defines its differences with other places in the city representing its unique cultural character.

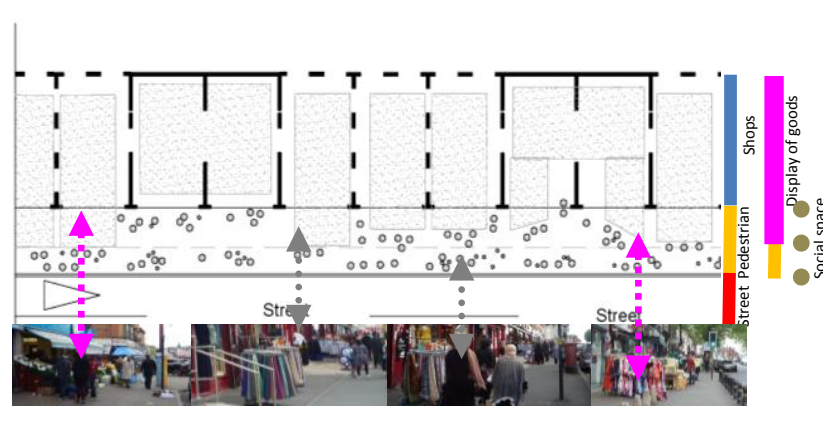

Diagram 1: based on mapping the observation in the main street of four Muslim neighbourhoods displaying the socio-spatial character of the place.

Fig. 3:

Utilisation of space in Muslim neighbourhoods in Birmingham

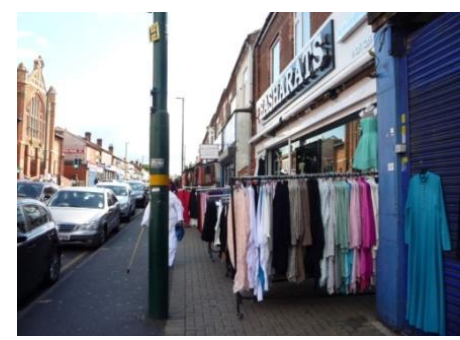

Alum Rock Road

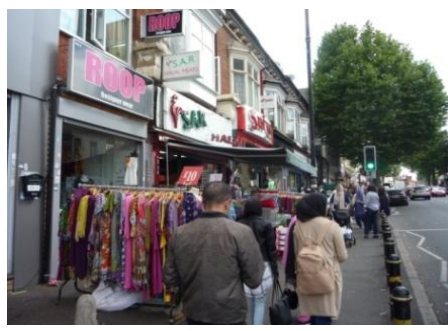

Stratford Road, Spark hill

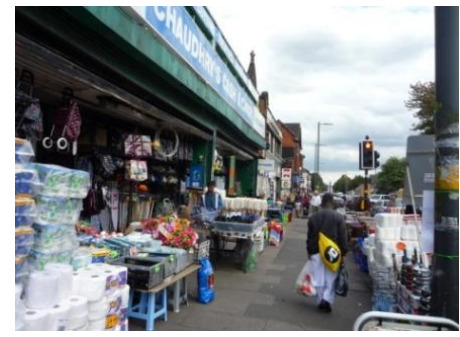

Coventry Road, Small Heath

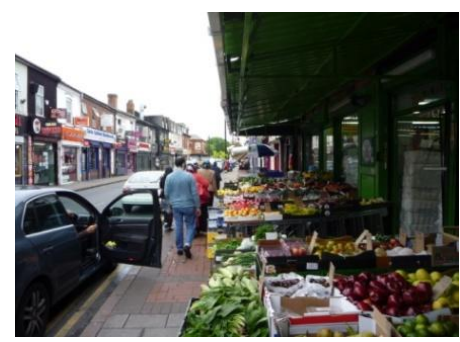

Lady pool Road, Sparkbrook

The business expansion of shops selling daily needs of people and displaying clothes and household furniture has changed the character of the street into a long linear exhibition place flanked by items of the daily needs and interests of people. 
$5^{\text {th }}$ International Conference on Civil Engineering, Architecture and Urban Planning Elites

Despite its chaotic spatial appearance, one can notice how the pattern of peoples' behaviour nicely fits within this disorder demonstrating a unique socio-spatial pattern.

The main market streets in these neighbourhoods are social and leisure places for ethnic people wondering as well as places for cultural events and practices. Here, as Hillier and Hanson (2005) explain, we see the spatial character of the street as a theatre of the everyday life of the people where the ordering of space represents its unique cultural dimension. All signs, sounds, smell, and behaviour represent their cultural identity through reference to their homeland. These ethnic neighbourhood streets demonstrate the embodiment of cultural and social practices in space representing the social life of space.

The identity of neighbourhoods of ethnic groups with rich historical and cultural background is further represented by their religious buildings. Mosques in the Muslim and Temples in the Indian neighbourhoods introduce the cultural identity of the area to the visitors.

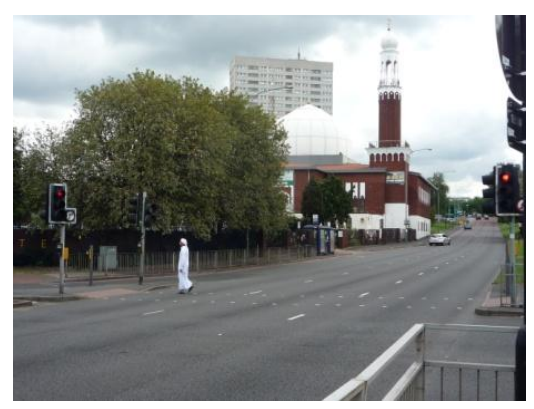

Central mosque, Highgate

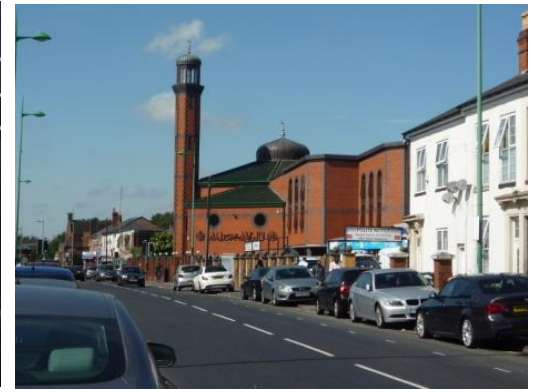

Central Mosque, Lozells

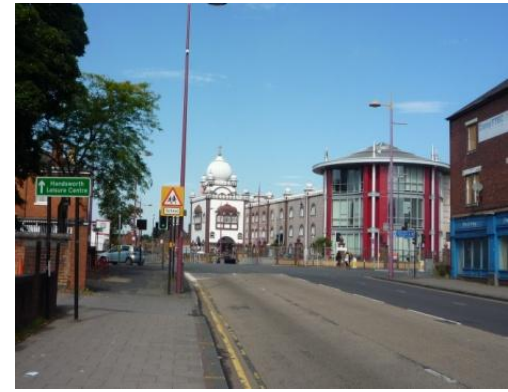

Hindu temple, Handsworth

Fig. 4: Religious bâfesfngt in the cultural minority neighboutfixads ievernting that bind mempers or eacn group together, preserving their traditional cultural and religious norms representing their ethnic identity.

The case study demonstrated the distinctive character of public spaces within the Muslim ethnic groups in Birmingham. It showed unique character of these places have been formed by the integration of the groups historical and socio-cultural norms to the present. And it is this reference to the cultural history which conveys meaning and sense of familiarity revealing their cultural identity.

\section{Conclusion}

As was mentioned earlier, many large cities in Europe have become a multicultural society including gropes with different racial and ethnic background. Points highlighted in this paper - ethnic grouping, cultural norms, identity, and social space- are shared by all ethnic groups and apply to all multicultural cities.

One noticeable impact of transformation from a single to the multicultural society, as we have seen in the case of Birmingham, is the formation of different ethnic neighbourhoods with specific social and physical characteristics. The clustering of ethnic groups with the similar cultural background, country of origin and religion, has 
$5^{\text {th }}$ International Conference on Civil Engineering, Architecture and Urban Planning Elites

enabled them to form a close community for practicing their cultural norms. The formation of the closed community has also provided the opportunity for ethnic groups to re-organise the existing urban places to social spaces suitable for practicing their cultural norms. This culturalisation of the space with reference to a combination of the social, spatial, and cultural background of the group distinguishes the unique character of the place establishing its identity. Consequently, although these neighbourhoods are parts of the Birmingham city, however, their unique socio-spatial characteristics, indicate their differences with the rest of the city. And these differences constrain cross-cultural interaction leading in some cases to marginalisation and social exclusion affecting the social structure of the city.

An important point to address here is: how to achieve social cohesion in a multicultural city? I have chosen the term 'social cohesion' which is formed through recognition of cultural norms of different ethnic groups within the city promoting social cooperation and bounding a society together. The simple answer to the above question is by recognition of socio-cultural differences and formation of a shared identity creating a sense of belonging for all the inheritance.

Approaches to address the above question have so far been through economic development since most residents of the ethnic neighbourhoods are among the lower income people. However, the economic-based approaches have so far had little impact in promoting a cohesive urban society, since those low percentages who manage to increase their income level and move out of neighbourhood are still socially attached to it. It is important to recognise that a sustainable city includes three factors of social, economic, and environmental sustainability.

For promoting a cohesive society, we have to remove the existing barriers that separate clusters within the city. This could be addressed through a: recognition, not rejection, of prevailing social and cultural difference within the urban society; and $b$ : reconsidering approaches to the city planning, urban development, and regeneration schemes to provide a suitable environment for different cultural groups to create a sense of belonging for all.

Removing these barriers require reconsidering approaches to the city planning, urban development, and regeneration schemes. We must recognise that the change of social landscape of the city from a single to the multiple social environments requires a more complex approach to the city. This means not focussing solely on economic development, building commercial and high-rise office blocks in the city centre, but also paying attention to the social landscape of the city.

Addressing this complex issue in practice requires a better understanding of the important role of the urban environment in softening the notion of inclusiveness among ethnic groups promoting the development of a new shared identity for the younger generation. Such an understanding enables us to recognise that our planning and design approaches require certain flexibilities and modification in the context of different social groups. This calls for the inclusion of variable standards in the planning and design regulations. 
$5^{\text {th }}$ International Conference on Civil Engineering, Architecture and Urban Planning Elites

\section{References:}

Agnew, J. A., Mercer, J. \&Sopher, D. E. (Eds.) (1984) The City in Cultural Context (pp. 5075). Boston MA. London: Allen \& Unwin.

Alcoff L.M. \&Mendieta E. (ed) (2003). Identities, Race, Class, Gender and Nationality. Blackwell Publishing.

Benwell, B. \& Stokoe, E. (2007) Discourse and Identity. Edinburgh University Press. Duncan, J. \& Ley, D. (1993) Place/Culture/Representation. London: Routledge.

Elliot, T. S. (1962) Notes towards the Definition of Culture. London: Faber and Faber Limited.

Freud, S. (1923) The Ego and the Id, in: Kidd, W. (2002) Culture and Identity. Palgrave Macmillan.

Gilbert, A. \& Gugler, J. (1992) Cities, poverty and development. Oxford: Oxford University Press.

Gieseking, JJ. \& Mangold, W. (Eds)(2014) The people, Place, and Space Reader. London: Routledge.

Hague, C. \& Jenkins, P. (Eds) (2005) Place Identity, Participation and Planning. London: Routledge.

Hall, S. and Du Gay, P. (Eds) (1996) Question of Cultural Identity. London: Sage.

Hillier, B. and Hanson, J. (2005). The logic of space. Cambridge: Cambridge University Press.

Honeyford, R. (1988) Integration or Disintegration? Towards a Non-racist Society. London: the Claridge Press.

Jenks, C. (1993) Culture. London, Routledge.

Jiven, G. \& Larkham, P. J. (2003) Sense of Place, Authenticity and Character: A Commentary. Journal of Urban Design, (2003) Volume 8, Issue 1, February 2003, pp 678.

Kazimee, B. A. \& Rahmani, A.B. (2003) Place, meaning, and form in the architecture and the urban structure of Eastern Islamic cities. Lampeter: The Edwin Mellen Press, Ltd.

Kham, M. (2000) Tahiti Intertwined: Ancestral Land, Tourist Postcard, and Nuclear Test Site. American Anthropologist, New Series, 102(1):7 26. http://onlinelibrary. Wiley.com

Kidd, W. (2002) Culture and Identity. Basingstok: Palgrave Macmillan.

Knox, P. \& Pinch, S. (2010) Urban Sociology: An Introduction. Prentice Hall, sixth Edition.

Lapidus, P. Traditional Muslim Cities: structure and change. In Brown, L. C. (1973) From Madinah to Metropolis. Princeton, New Jersey, The Darwin Press:53.

Lewis, J. (2002) Cultural Studies - The Basics. London: Sage Publications.

Mitchell, D. (2000) Cultural Geography: A Critical Introduction. Oxford: Blackwell Publishers.

Moghaddam, F. M. (2002) The Individual and society, a cultural integration. Worth Publisher. 
Proshansky, H. M., Fabian, A. k. \& Kaminoff, R (1983) Place-Identity: Physical World Socialization of the Self, in: Gieseking, JJ. \&Mangold, W. (Eds) (2014) op Cit.

Rapoport, A. (1977) Human aspects of urban form-Towards a man-environment approach to urban form. Oxford: Pergamon Press.

Runco, M. A.(2014)Creativity Theories and Themes: Research, Development, and Practice. London: Academic Press.

Seufert, G. (1983) Between religion and ethnicity: a Kurdish-Alevi tribe in globalizing Istanbul, in Öncü, A. \& Weyland, P. (ed) (1997) op cit.

Tonkiss, F. (2005) Space, the City and Social Theory: Social Relations and Urban Forms. Cambridge, Polity Press.

Valsiner, J. (2007) Culture in Mind and Societies: Foundation of Cultural Psychology. London: Sage Publications.

Watson, G. B. \& Bentley, I. (2007) Identity and design. Oxford: ButterworthHeinemaan.

Wesener, A. (2013) The Good, the Bad, the Authentic: An evaluation of concepts, experiences, and considered values of authenticity of place in the context of the post-industrial city. PhD thesis. Weimar: Bauhaus university.

\section{Internet Sources:}

(https://www.birmingham.gov.uk/info/50065/population and census/1003/populatio $\mathrm{n}$ in birmingham/3)

Allen, C 2016. https://www.huffingtonpost.co.uk/dr-chris-allen/Birminghammuslim b 12567710.html. 